\title{
STUDY OF A DISCRETIZED FRACTIONAL-ORDER ECO-EPIDEMIOLOGICAL MODEL WITH PREY INFECTION
}

\author{
Shuvojit Mondal, Xianbing CAO And NANDADUlal BaIRAGi
}

\begin{abstract}
In this paper, an attempt is made to understand the dynamics of a three-dimensional discrete fractional-order eco-epidemiological model with Holling type II functional response. We first discretize a fractional-order predator-prey-parasite system with piecewise constant arguments and then explore the system dynamics. Analytical conditions for the local stability of different fixed points have been determined using the Jury criterion. Several examples are given to substantiate the analytical results. Our analysis shows that stability of the discrete fractional order system strongly depends on the step-size and the fractional order. More specifically, the critical value of the step-size, where the switching of stability occurs, decreases as the order of the fractional derivative decreases. Simulation results explore that the discrete fractional-order system may also exhibit complex dynamics, like chaos, for higher step-size.
\end{abstract}

Mathematics subject classification (2010): 34A08, 26A33, 34K37, 44A20.

Keywords and phrases: Fractional order differential equation, ecological model, discrete fractionalorder system, local stability, bifurcation, chaos.

\section{REFERENCES}

[1] S. Samko, A. Kilbas, O. Marichev, Fractional Integrals and Derivatives: Theory and Applications, Gordon and Breach Science Publishers, Yverdon, (1993).

[2] F.A. Rihan, S. Lakshmanan, A.H. Hashish, R. RakkiYappan, E. Ahmed, Fractional-order delayed predator-prey systems with Holling type-II functional response, Nonlinear Dynamics, 80, 1-2 (2015), 777-789.

[3] J. T. Machado, V. Kiryakova, F. Mainardi, Recent history of fractional calculus, Commun. Nonlinear Sci. Numer. Simulat., 16, (2011), 1140-1153.

[4] I. Matychyn, V. Onyshchenko, Time-optimal control of fractional-order linear systems, Fract. Calc. Appl. Anal. 18, 3 (2015), 687-696.

[5] R. E. Gutierrez, J. M. Rosario, J. T. Machado, Fractional Order Calculus: Basic Concepts and Engineering Applications, Math. Prob. Eng. (2010); DOI: 10.1155/2010/375858.

[6] S. Abbas, M. Benchohra, G. M. N'Guerekata, Topics in Fractional Differential Equations, Springer Science \& Business Media, (2012).

[7] S. DAS, Introduction to Fractional Calculus for Scientists and Engineers, Springer, (2011).

[8] M. L. RichARD, Fractional calculus in bioengineering, Redding: Begell House, (2006).

[9] Y. LI AND Q. ZHANG, Blow-up and global existence of solutions for a time fractional diffusion equation, Fract. Calc. Appl. Anal. 21, 6 (2018), 1619-1640.

[10] J. Munkhammar, Chaos in a fractional order logistic map, Fract. Calc. Appl. Anal. 16, 3 (2013), $511-519$.

[11] M. C. TRipathy, D. Mondal, K. Biswas, S. Sen, Experimental studies on realization of fractional inductors and fractional order bandpass filters, Int. J. Circuit Theory and Applications, 43, 9 (2015), $1183-1196$.

[12] P. J. Torvik, R. L. BAgley, On the appearance of the fractional derivative in the behaviour of real materials, J. Appl. Mechanics, 51, 2 (1984), 294-298.

[13] J. A. Sabatier, O. P. Agrawal, J. T. Machado, Advances in Fractional Calculus, Dordrecht: Springer, (2007). 
[14] A. Boukhouima, K. Hattaf, N. Yousfi, Dynamics of a fractional order HIV infection model with specific functional response and cure rate, Int. J. Diff. Equations, 2017, (2017).

[15] E. Ahmed, A. M. A. El-SAYEd, H. A. A. El-SAKA, Equilibrium points, stability and numerical solutions of fractional-order predator-prey and rabies models, J. Math. Anal. Appl., 325, (2007), 542553.

[16] S. RanaA, S. Bhattacharyaa, J. Pal, G. M. N'Guerekata, J. Chattopadhyay, Paradox of enrichment: A fractional differential approach with memory, Physica A., 392, (2013), 3610-3621.

[17] Z. CUI, Z. YANG, Homotopy perturbation method applied to the solution of fractional Lotka-Volterra equations with variable coefficients, J. Mod. Meth. Numer. Math., 5, (2014), 1-9.

[18] S. Mondal, N. BAiragi, G. M. N'GuerekATA, Global stability of a Leslie-Gower-type fractional order tritrophic food chain model, Fractional Differential Calculus, 9, 1 (2019), 149-161.

[19] S. Mondal, N. Bairagi, A. LAhIRI, A fractional calculus approach to Rosenzweig-MacArthur predator-prey model and its solution, J. Mod. Meth. Numer. Math., 8, 1-2 (2017), 66-76.

[20] J. HuO, H. ZHAO, L. ZHU, The effect of vaccines on backward bifurcation in a fractional order HIV model, Nonlinear Anal. RWA. 26, (2015), 289-305.

[21] H. L. LI, L. Zhang, C. Hu, Y. L. JiAng, Z. Teng, Dynamical analysis of a fractional-order predator-prey model incorporating a prey refuge, J. Appl. Math. Comput. (2016); DOI: $10.1007 / \mathrm{s} 12190-016-1017-8$.

[22] C. VARGAS-DE-LEON, Volterra-type Lyapunov functions for fractional-order epidemic systems, Commun. Nonlinear Sci. Numer. Simul. 24, (2015), 75-85.

[23] S. Mondal, A. Lahiri, N. BAiragi, Analysis of a fractional order eco-epidemiological model with prey infection and type 2 functional response, Math. Meth. Appl. Sci. 40, 18 (2017), 6776-6789.

[24] K. Hattaf, A. A. Lashari, B. El Boukari, N. Yousfi, Effect of discretization on dynamical behavior in an epidemiological model, Differential Equations and Dynamical Systems, 23, 4 (2015), 403-413.

[25] M. SEKIGUCHI, E. IshIWATA, Global dynamics of a discretized SIRS epidemic model with time delay, Journal of Mathematical Analysis and Applications, 371, 1 (2010), 195-202.

[26] Q. Chen, Z. TEng, L. WANG, H. JIAng, The existence of codimension-two bifurcation in a discrete SIS epidemic model with standard incidence, Nonlinear Dyn. 71, (2013), 55-73.

[27] Z. Hu, Z. TENG, L. WANG, H. JIANG, Stability analysis in a class of discrete SIRS epidemic models, Nonlinear Anal.: Real World Appl. 13, (2012), 2017-2033.

[28] M. Biswas, N. BAIRAgi, Discretization of an eco-epidemiological model and its dynamic consistency, Journal of Difference Equations and Applications, 23, 5 (2017), 860-877.

[29] S. Ghorai, P. Chakraborty, S. Poria and N. Bairagi, Dispersal-induced pattern forming instabilities in host-parasitoid metapopulations, Nonlinearity, (2020), DOI.org/10.1007/s11071-02005505-w.

[30] F. M. Atici, P. W. Eloe, A transform method in discrete fractional calculus, Int. J. Difference Equations, 2, 2 (2007), 165-176.

[31] C. Fulai, L. Xiannan, Z. Yong, Existence results for nonlinear fractional difference equation, Advances in Difference Equations, 2011, (2011); DOI: 10.1155/2011/713201.

[32] G. C. Wu, D. Baleanu, Chaos synchronization of the discrete fractional logistic map, Signal Processing, 102, (2014), 96-99.

[33] A. A. Elsadany, A. E. Matouk, Dynamical behaviors of fractional-order Lotka Volterra predatorprey model and its discretization, J. Appl. Math. Comput. 49, (2015), 269-283.

[34] J. Alzabut, T. Abdeljawad, D. Baleanu, Nonlinear delay fractional difference equations with applications on discrete fractional Lotka-Volterra competition model, J. Comput. Anal. Appl. 25, 5 (2018), 889-898.

[35] A.G. M. Selvam, R. Janagaraj, Numerical Analysis of a Fractional Order Discrete Prey-Predator System with Functional Response, In. J. Engineering \& Technology. 7, 4.10 (2018), 681-684.

[36] Y. SHI, Q. MA AND X. DIng, Dynamical behaviors in a discrete fractional-order predator-prey system, Filomat, 32, 17 (2018), 5857-5874.

[37] S. M. Salman, On a Discretized Fractional-Order SIR Model for Influenza, Progress in Fractional Differentiation and Application, 3, 2 (2017), 163-173.

[38] A. M. Abdelaziz, A. I. Ismail, F. A. Abdullah And M. H. Mohd, Bifurcations and chaos in a discrete SI epidemic model with fractional order, Advances in Difference Equations. 1 (2018), 1-19. 
[39] A. Khan, J. F. Gomez-Aguilar, T. S. Khan, H. Khan, Stability analysis and numerical solutions of fractional order HIV/AIDS model, Chaos, Solitons and Fractals, 122, (2019), 119-128.

[40] A. Khan, T. Abdeljawad, J. F. GomeZ-Aguilar, H. Khan, Dynamical study of fractional order mutualism parasitism food web module, Chaos, Solitons and Fractals, 134, (2020), 109685.

[41] S. MONDAL, M. BISWAS AND N. BAIRAGI, Local and global dynamics of a fractional-order predator-prey system with habitat complexity and the corresponding discretized fractional-order system, J. Applied Mathematics and Computing, (2020); DOI: https://doi.org/10.1007/s12190-02001319-6.

[42] A. Khan, J. F. GomeZ-Aguilar, T. Abdeljawad, H. Khan, Stability and numerical simulation of a fractional order plant-nectar-pollinator model, Alexandria Engineering Journal, 59, 1 (2020), 49-59.

[43] R. P. Agarwal, A. M. A. El-Sayed, S. M. Salman, Fractional-order Chua's system: discretization, bifurcation and chaos, Advances in Difference Equations, 1, (2013), 320.

[44] A. M. A. EL-SAYED, S. M. SALMAN, On a discretization process of fractional-order Riccati differential equation, J. Fract. Calc. Appl. 4, 2 (2013), 251-259.

[45] A. G. M. Selvam, D. A. Vianny, Behavior of a Discrete Fractional Order SIR Epidemic model, International Journal of Engineering and Technology, 7, 4.10 (2018), 675-680.

[46] Z. F. El RAheEm, S. M. Salman, On a discretization process of fractional-order logistic differential equation, Journal of the Egyptian Mathematical Society, 22, 3 (2014), 407-412.

[47] J. Chattopadhyay, N. Bairagi, Pelicans at risk in Salton sea-an eco-epidemiological model, Ecological Modelling, 136, (2001), 103-112.

[48] S. N. Elaydi, An Introduction to Difference Equations, Springer, New York, USA, (1999).

[49] N. BAiragi, R. R. SARKAR, J. ChattopadhyAy, Impacts of incubation delay on the dynamics of an eco-epidemiological system-a theoretical study, Bulletin of Mathematical Biology, 70, 7 (2008), 2017-2038.

[50] R. K. Upadhyay, N. Bairagi, K. Kundu, J. Chattopadhyay, Chaos in eco-epidemiological problem of the Salton Sea and its possible control, Applied Mathematics and Computation, 196, 1 (2008), 392-401. 